\title{
Beyond correlation: integrating environmentally and behaviourally mediated processes in models of marine mammal distributions
}

\author{
Daniel M. Palacios ${ }^{1,6, *}$, Mark F. Baumgartner ${ }^{2}$, Kristin L. Laidre ${ }^{3}$, Edward J. Gregr ${ }^{4,5}$ \\ ${ }^{1}$ Environmental Research Division, NOAA/NMFS/Southwest Fisheries Science Center, 1352 Lighthouse Avenue, \\ Pacific Grove, California 93950, USA \\ ${ }^{2}$ Woods Hole Oceanographic Institution, Biology Department, 266 Woods Hole Road, Woods Hole, Massachusetts 02543, USA \\ ${ }^{3}$ Polar Science Center, Applied Physics Laboratory, University of Washington, 1013 NE 40th Street, Seattle, \\ Washington 98105, USA \\ ${ }^{4}$ SciTech Environmental Consulting. 2136 Napier Street, Vancouver, British Columbia V5L 2N9, Canada \\ ${ }^{5}$ Institute for Resources, Environment, and Sustainability, University of British Columbia, 2202 Main Mall, Vancouver, \\ British Columbia V6T 1Z4, Canada \\ ${ }^{6}$ Present address: Marine Mammal Institute, Hatfield Marine Science Center, Oregon State University, \\ 2030 SE Marine Science Drive, Newport, Oregon 97365, USA
}

\begin{abstract}
Marine species distribution modeling has seen explosive growth in recent years, and the Endangered Species Research Theme Section entitled 'Beyond marine mammal habitat modeling: applications for ecology and conservation' demonstrates that the field of marine mammalogy has been no exception. For the past decade, marine mammal ecologists have been developing habitat models with increasing proficiency and sophistication. However, these efforts have largely focused on correlative analyses of observed species-environment associations, which often have low explanatory power due to the absence of critical, but unaccounted for processes that are important drivers of animal distributions. Here we provide an overview of these processes, advocate for directed studies (e.g. tagging, prey sampling, focal follows, physiological assessment) to address how the processes influence species' distributions, and challenge the modeling community to incorporate these results into their efforts. We also identify a progression of modeling stages from correlative to confirmatory to mechanistic that should lead us to formulate increasingly robust and accurate predictions of species distributions rooted in greater ecological understanding. Given the on-going risks to marine mammals from human activities and climate change, such models are needed for conservation and management now more than ever.
\end{abstract}

KEY WORDS: Marine mammals · Species distribution - Modeling · Habitat suitability Species-environment associations $\cdot$ Correlative $\cdot$ Mechanistic $\cdot$ Hierarchical

\section{INTRODUCTION}

Over the past few decades, correlative models describing species distributions as a function of environmental variables have become commonplace. This has been enabled by several factors, including the development of flexible modeling techniques, the in- creasing power of desktop computing, the accessibility of statistical and mapping software and improved access to digital repositories of environmental and spatial data (Guisan \& Zimmermann 2000, Elith et al. 2006, Robinson et al. 2011). The papers in the Endangered Species Research Theme Section 'Beyond marine mammal habitat modeling: applications for 
ecology and conservation' clearly demonstrate that the marine mammal research community has embraced these tools, and is applying them with increasing proficiency and sophistication (Gregr et al. 2013, this Theme Section).

Marine mammal habitat models typically predict the spatial distribution or abundance of a species based on correlations between animal observations and attributes of the physical marine environment (e.g. seafloor terrain, sea surface temperature, proximity to the ice edge) or proxies of dynamic oceanographic processes that may directly or indirectly aggregate prey (Redfern et al. 2006). This approach often makes 2 implicit assumptions with regard to the environmental variables: (1) they adequately capture the underlying environmental gradients to which a species responds, and (2) they reasonably represent conditions that lead to enhanced feeding opportunities. These assumptions, and the focus on foraging success, reflect the limits of our understanding of how marine mammals interact with their environment as well as our ability to directly measure the prey field at scales relevant to a foraging predator.

The correlative approach has generated considerable insight into the distribution of marine mammal species and their potential foraging areas. However, our models continue to capture only a small portion of the observed variability in species' occurrence or abundance. For example, the deviance explained (a measure of model fit) by models published in this Theme Section was generally below $50 \%$, and for many models it was less than $25 \%$. While progress in analytical approaches (e.g. Gerrodette \& Eguchi 2011, this Theme Section) now allows us to model the uncertainty in the observational ('sampling') processes (i.e. the factors that affect visual detection: Barlow et al. 2001, Williams et al. 2007), and the measurement error in the environmental covariates (Gomis \& Pedder 2005, Gomis et al. 2005) separately from the 'state' process of scientific interest (marine mammal density or distribution), we believe the limited explanatory power of correlative approaches is due fundamentally to the omission of critical environmental and behavioural processes that directly affect marine mammal distributions.

We argue that the elucidation of such processes and their subsequent incorporation into habitat models will significantly improve our ability to predict species' distributions. Here, we (1) review processes likely to influence marine mammal distributions, (2) describe how directed studies can help investigate and understand those processes prior to modeling, and (3) challenge the marine mammal modeling community to adopt new methods and approaches for integrating environmentally and behaviourally mediated processes in their species distribution models.

\section{FACTORS INFLUENCING THE SPATIAL DISTRIBUTION OF MARINE MAMMALS}

Today's habitat models attempt to describe marine mammal distributions as a function of mostly physiographic or physical oceanographic environmental variables such as depth, sea surface temperature, sea surface height or the local gradients of these, even though it is generally believed that marine mammals do not respond to them directly. Indeed, marine mammal distributions are influenced by many factors (Forcada 2008), and while some can be directly related to such physical variables (e.g. prey production), others may have very little to do with environmental conditions (e.g. predator avoidance, competition, foraging specialisation). Here we identify what we believe to be the most important processes influencing marine mammal distributions in the context of predictive modeling. We distinguish between those that are principally environmental (i.e. those that influence prey distribution) and those that are behavioural (i.e. those that arise from social, foraging or reproductive activities; Fig. 1). Recognising that these processes occur over characteristic, but overlapping, spatial extents, we refer to them as local scale (metres to tens of kilometres), mesoscale (tens to hundreds of kilometres) and large scale (hundreds to thousands of kilometres).

Behavioural factors have been largely ignored in habitat models for good reason: they are difficult to study and the relationship between individual behaviour and population distribution is poorly understood. There are also interactions between processes that make incorporation of these factors in distribution models challenging. For example, socialising and prey availability may sometimes be linked (Croll et al. 2002), or species may have such high site fidelity that active habitat selection is difficult to determine (Laidre et al. 2004). In addition, human activities can also affect marine mammal behaviour and distribution through direct removal (e.g. industrial whaling and sealing), incidental mortality in fisheries (bycatch), habitat degradation or disturbance (e.g. shipping, seismic exploration, military activities, offshore energy developments), even leading to the extinction of species (Turvey et al. 2007, McClenachan \& Cooper 2008). While we acknowledge the pervasive influence 


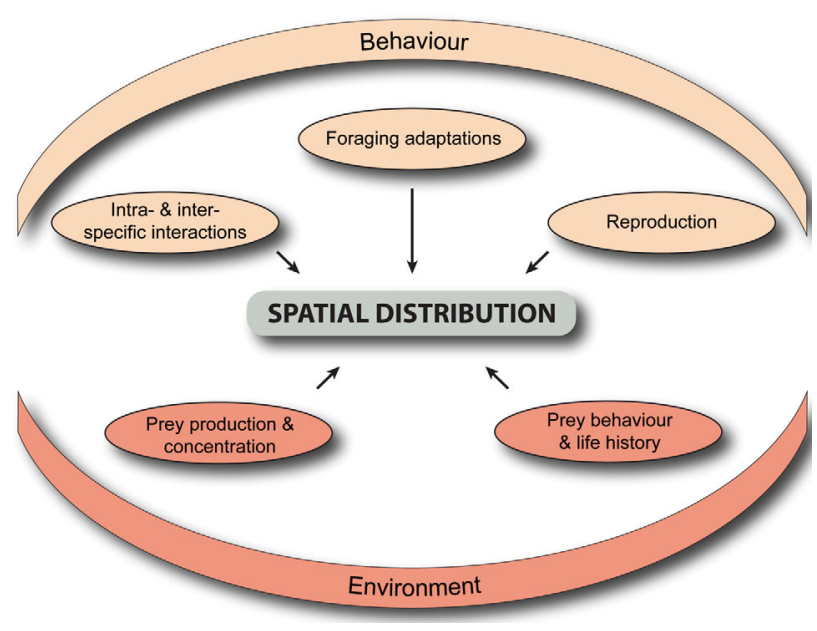

Fig. 1. Behaviourally and environmentally mediated processes that influence marine mammal distributions

of humans in marine systems (see Verity et al. 2002), our focus here is only on natural drivers of marine mammal distribution.

\section{Prey production and concentration}

The single most desirable independent variable in marine mammal habitat modeling is prey abundance (or characteristics of prey patches, such as density or depth; see Benoit-Bird et al. 2013). Our sense is that researchers intuitively expect that the spatial distribution of a predator will match with near perfection a map of prey abundance across all scales. However, even if we were interested only in foraging behaviour, a perfect match between predator and prey would only be possible if prey abundance could be accurately and synoptically measured in 3 dimensions at spatial scales relevant to foraging marine mammals (i.e. decimetre resolution across horizontal extents of tens to hundreds of metres and vertical extents of metres). However, such prey sampling is presently impossible; instead, sampling is done on scales unlikely to reflect the true abundance of prey available to marine mammals (e.g. Torres et al. 2008, Hazen et al. 2011). Furthermore, predator distributions are only likely to match those of their prey if the predators are, at all times, focused on areas with the highest prey densities. In reality, a number of other non-foraging activities like migrating, socialising or breeding also influence species' movements and distributions (e.g. Rasmussen et al. 2007, Blasi \& Boitani 2012 in this Theme Section, Keller et al. 2012 in this Theme Section, Laidre et al. 2012).
Nevertheless, a predator's distribution must at times correlate with prey abundance, which is largely determined by production and concentration processes that, in turn, are strongly influenced by physical processes. For example, the local processes of upwelling or vertical mixing (via wind forcing or convection) can stimulate primary production by introducing nutrients in surface waters, while dynamic mesoscale features such as eddies or fronts can aggregate secondary producers into discrete patches that can be exploited by predators (Etnoyer et al. 2006, Palacios et al. 2006, Moore \& Lien 2007, Wingfield et al. 2011). Over large scales, physical processes dictate regional biogeography, which ultimately governs the distributional ranges of marine prey and their predators. This is why variables thought to represent such processes are frequently used as proxies in modern marine mammal habitat models (e.g. Kaschner et al. 2006). Unfortunately, the links between these physical processes and prey abundance via production and concentration are very poorly understood in most parts of the ocean. Even for zooplankton that feed on phytoplankton, there can be significant temporal and spatial lags between production and consumption by a zooplanktivorous marine mammal. For example, the calanoid copepods consumed by a North Pacific right whale Eubalaena japonica on a particular day in a particular location may have been 'produced' (i.e. laid as eggs) hundreds of kilometres away, months prior or even during the previous year (Gregr \& Coyle 2009). For prey species at higher trophic levels (e.g. nekton such as squid and fish), such lags can be even more pronounced (e.g. Jaquet \& Whitehead 1996, Walli 2007, Grémillet et al. 2008).

\section{Prey behaviour and life history}

Prey exhibit a myriad of feeding and predator avoidance strategies that can influence their availability to marine mammals. Schooling behaviour in krill and baitfish can make such prey much easier to capture by rorqual whales, and diel vertical migration (DVM) can bring deep-dwelling organisms closer to the surface for feeding by shallow-diving species (Benoit-Bird \& Au 2003, 2006). Spatial or temporal variability in these species-specific behavioural processes can drive similar variability in the distribution of marine mammals. Ontogenetic changes in prey size, energetic content or behaviour associated with various life history strategies can also influence marine mammal foraging behaviour. For 
example, some zooplankton prey species deposit lipids during certain life history stages to survive later periods of low food resources (Hirche 1996), thus becoming desirable as food for marine mammals only during specific developmental phases (Wishner et al. 1995, Baumgartner \& Mate 2003, Laidre et al. 2007, Gregr \& Coyle 2009). Finally, prey behaviour is often thought of as a local-scale process, but nektonic prey can often move across mesoscales (e.g. Slotte 1999).

\section{Reproduction}

Large-scale migrations motivated by mating and calving are well known for many marine mammal species, yet little is known about the extent to which local-scale movements are motivated by mating opportunities (Laidre et al. 2012). Further, the movements and behaviour of different demographic groups are likely driven by different requirements. For example, prey densities or sizes required for feeding by adult males may be quite different than for reproductive females, and these differences can drive changes in the spatial distribution of the population (e.g. Le Boeuf et al. 2000, Engelhaupt et al. 2009, Heide-Jørgensen et al. 2010).

\section{Foraging adaptations}

When feeding, the occurrence of a marine mammal in a particular location can be thought of as the interaction between prey availability and the animal's foraging adaptations. For instance, if highly abundant forage fish are widely dispersed, a rorqual may have difficulty feeding because it is morphologically and behaviourally adapted to lunge feeding (Goldbogen et al. 2013) and cannot feed on 1 fish at a time the way an odontocete might (Johnson et al. 2009). The diving and sensory physiology of a marine mammal, as well as its associated diving and foraging behaviour, combine to dictate what aspects of the water column are important (e.g. mesopelagic prey for deep divers, epipelagic prey for visual hunters, benthic prey for bottom feeders, thin prey layers for ram filter feeders, dense prey schools for lunge feeders). Therefore, the processes governing prey availability at particular depths likely influence marine mammal foraging and spatial distribution (e.g. the thickness of the surface mixed layer may have no influence on the distribution of elephant seals Mirounga spp. that feed at 200 to $600 \mathrm{~m}$, whereas subsurface features and boundaries between deep water masses appear to be important; Biuw et al. 2007, Robinson et al. 2012)

\section{Intra- or interspecific interactions}

Long-term familial or social associations between individuals have been widely documented in marine mammals (e.g. Wells et al. 1987, Connor et al. 1992, Parsons et al. 2009, Ramp et al. 2010), suggesting that the movements of individuals can be influenced by the distribution of conspecifics. Croll et al. (2002) hypothesised that the vocalizations of male fin whales are intended to advertise the presence of prey patches to widely dispersed females across mesoscales, in an effort to attract them for socialising and possibly mating. The low-frequency calls of baleen whales are particularly well suited to coordinating movement and activities among individuals across such spatial extents (i.e. the 'range herd' concept of Payne \& Webb 1971). Over shorter distances, acoustic and visual contact helps maintain cohesion among individuals in groups wherein the movements of individuals are highly correlated with conspecifics (e.g. Janik \& Slater 1998).

Marine mammals are subject to predation by sharks and other marine mammals (Estes et al. 1998, Heithaus 2001, Laidre et al. 2006), thus predator avoidance must have some influence over their movements and distribution (the 'seascapes of fear' concept of Wirsing et al. 2008). Jefferson et al. (1991) reviewed a wide variety of marine mammal responses to the presence of killer whales Orcinus orca, including active defence, fleeing, hiding or changing group size. Such behavioural responses can often indicate a change in distribution owing to predator avoidance. A variety of agonistic social interactions between marine mammal species are also prevalent (Shelden et al. 1995, Palacios \& Mate 1996, Ciano \& Jørgensen 2000, Frantzis \& Herzing 2002, Rossi-Santos et al. 2009), and, while poorly understood, they probably play a role in shaping species' distributions at local scales. Across taxa, multi-specific interactions between marine mammals, fish and birds are also commonly observed (e.g. Pitman \& Ballance 1992, Bearzi 2006, Vaughn et al. 2007, Haynes et al. 2011, Scott et al. 2012), and while these interactions are even less well understood, they may influence the spatial distribution of a species through processes such as mutualism, commensalism or competition. For example, based on an observed negative relationship between the abundance of sei whales Bal- 
aenoptera borealis and the occurrence of DVM in the copepod Calanus finmarchicus, Baumgartner et al. (2011) speculated that the occurrence of zooplanktivorous fish influenced the distribution of sei whales by inducing DVM behaviour in their common copepod prey.

\section{PROCESS STUDIES}

To understand better how each of the processes above affects the spatial distribution of marine mammals, we suggest that directed studies are needed to elucidate how these processes influence marine mammal behaviour. These 'process studies' need not explicitly consider spatial distribution, but should instead focus on those aspects of the environment and the animals' behaviour that might influence spatial distribution. Such studies should seek to quantify the interactions between the species of interest and its environment, prey, conspecific behaviour and (or) non-prey species that may affect occurrence, individual movements or foraging behaviour. They may employ a wide variety of techniques such as short-term tagging, long-term tagging, focal follows, targeted prey and oceanographic sampling, and physiological observations. The results of these studies can then be used to (1) inform spatial models by refining model structure, (2) provide values for previously unknown or poorly constrained parameters or (3) identify novel independent variables. More generally, such studies will improve our ecological understanding of the many factors that may motivate changes in species distribution.

To illustrate, we consider the factors that might influence the behaviour and distribution of the sperm whale Physeter macrocephalus, a species that has proven notoriously difficult to model. Papastavrou et al. (1989) hypothesised that sperm whales dive to and feed in the oxygen minimum layer (OML) where slow-moving, easy-to-catch fish and cephalopods specifically adapted to a low-oxygen environment occur $\left(H_{1}\right)$. We further hypothesise that sperm whales will occur more frequently in areas where the OML is shallower because OML-associated prey will be nearer to the surface and therefore more accessible to the whales $\left(H_{2}\right)$. A short-term tagging study could be conducted to address $H_{1}$ by deploying electronic tags to record the whales' diving behaviour, and profiling a dissolved oxygen sensor repeatedly from a ship in proximity to the tagged whales. If $H_{1}$ is confirmed, OML depth could then be included in a model of sperm whale habitat suitability based on sighting surveys and simultaneous in situ oxygen profiling to address $H_{2}$. The use of OML depth in the model would be strongly justified by the results of the process study and would allow the unambiguous testing of a hypothesis about spatial distribution $\left(\mathrm{H}_{2}\right)$ based on fundamental ecological research.

Building on this process-oriented approach, Croll et al. (1998) advocated the integration of several independent yet coordinated process studies conducted at different space and time scales to develop a comprehensive understanding of what motivates the horizontal or vertical movement of a target species. To illustrate their approach, Croll et al. (1998) integrated the results from large-area sighting and oceanographic surveys, small-area surveys, hydroacoustic sampling, net sampling, faecal sampling and short-term tagging, to conclude that blue whales Balaenoptera musculus fed during the daytime on 2 species of euphausiids in 2 distinct depth strata (Thysanoessa spinifera between 0 and $50 \mathrm{~m}$ over the shelf, and Euphausia pacifica between 100 and $175 \mathrm{~m}$ off the shelf), and that the spatial distribution of blue whales was influenced by aggregations of these prey formed downstream of regions of persistent coastal upwelling and steep bottom topography. Other researchers have adopted this approach, for example, to examine the factors that influence the behaviour, occurrence and distribution of North Atlantic right whales Eubalaena glacialis by integrating data from spatial surveys, short-term tagging, zooplankton sampling and point surveys (Baumgartner \& Mate 2003, Baumgartner et al. 2003a,b), or to study spatial and temporal associations between bowhead whales Balaena mysticetus, zooplankton and phytoplankton in western Greenland using satellite tagging, short-term tagging, oceanographic surveys and zooplankton sampling (Laidre et al. 2007).

Because process studies require expertise and resources that are not typically found in the marine mammal community, we recommend establishing collaborations with oceanographers and (or) biologists with expertise in particular prey species. When resources are limited, process studies can be conducted incrementally to first identify prey species, then to elucidate processes that influence the behaviour and distribution of those prey species, and finally to examine the behaviour of the marine mammal species of interest with respect to the distribution and behaviour of their prey. The goal of these studies is to draw a tighter connection between ecological processes and marine mammal behaviour. Once a fundamental understanding of those connections is achieved, researchers can then investigate how those same pro- 
cesses influence marine mammal distribution. Statistical species-habitat models are well suited for this task, and we discuss below how confirmatory models can be used for the purpose of hypothesis testing.

\section{MOVING FROM CORRELATIVE TO MECHANISM-BASED PREDICTIONS}

Accurate predictions of marine mammal distributions are increasingly needed to inform conservation efforts, especially in light of current management frameworks like ecosystem-based management or marine spatial planning (e.g. Levin et al. 2009, Foley et al. 2010, Murawski et al. 2010). In response to these needs, marine species distribution modeling has seen an explosive growth in recent years (Robinson et al. 2011). However, the most commonly applied methods are correlative, and while correlations can suggest which predictors might be important, they provide little insight into the underlying mechanisms (Dormann et al. 2012). Correlative approaches should therefore be seen as an initial step in developing an understanding of the key processes. This understanding is essential if we wish to accurately predict and forecast species distributions, especially in the face of global climate change, as correlative relationships may not apply under different ocean climate conditions (Myers 1998), and models built upon them may become less accurate over time (Beaumont et al. 2008, Morin \& Lechowicz 2008, Cuddington et al. 2013).

Further, correlative approaches are primarily descriptive - their intent is to describe how much of the variability in the data can be explained with independent predictor variables, and to allow interpolation (i.e. predictions) between observed values. Extrapolations to different environments (i.e. forecasts), either in space or in time, are more problematic since observations are unavailable for model specification or evaluation. As such, extrapolations must assume that processes are stationary (i.e. invariant over time or space) and that the distribution of predictor variables is also the same in the forecast regions or time periods (Elith \& Leathwick 2009). Clearly, such assumptions may not always be true. These shortcomings underscore the need for alternative approaches that focus on describing causal relationships, such as mechanistic models. Also known as process-based models, mechanistic models are mathematical representations of biological systems that quantify the interactions between an organism and its environment through functional relationships using predictive algorithms (Elith \& Leathwick 2009, Kearney \& Porter 2009, Dormann et al. 2012). A shift to more mechanism-based distribution modeling is essential if, as a community, we are to make inferences about realised distributions instead of simply habitat suitability, or to make meaningful contributions to the understanding of how marine mammals will respond to a changing climate.

We identify and describe 3 distinct stages of distribution modeling to encourage and support this transition within the marine mammal community: correlative modeling, confirmatory modeling and mechanistic modeling. We hope that this discussion will help marine mammal ecologists better orient themselves in the sometimes bewildering field of species distribution modeling, and thus be better able to articulate their model objectives, analyse their data and interpret their model results in the most appropriate context.

\section{Correlative models}

Correlative models are often an essential first step to understanding how environmental conditions may influence a species' spatial distribution, especially where no a priori information on the species' ecology exists (e.g. for a poorly studied or cryptic species). As demonstrated by the collection of articles in this Theme Section, our community has made enormous progress in the last few decades. It is evident from these articles that we are paying closer attention to model scope, either through more thoughtful dependent variable specification (e.g. Lambert et al. 2011, Blasi \& Boitani 2012, both this Theme Section), or by isolating the habitat question to a specific context (e.g. Gregr 2011, Doniol-Valcroze et al. 2012, both this Theme Section). However, there are 2 principal areas where we feel further improvements can still be made.

Firstly, it is important to recognise that physical and biological oceanographic processes manifest themselves at characteristic spatio-temporal scales (Fauchald et al. 2000, Hewitt et al. 2007, Anderwald et al. 2012). Therefore, careful consideration of scales, the linkages among them and their relevance to a study's questions have implications for its sampling design, analytical approach and ultimately for the scope of its ecological conclusions (Wiens 1989). As a practical suggestion, it is often useful to examine the decorrelation scales of both dependent and independent variables (e.g. Doney et al. 2003, Hosoda \& Kawamura 2004, Boyce et al. 2010) prior to analysis, 
as this can yield insight into (1) the scale of important ecological processes relative to the 'input' resolution inherent in the sampling design, and (2) the appropriate scale at which to bin raw data for analyses and for the 'output' resolution of a study. Modellers might benefit from considering scaling as a form of averaging, and recognising that all variables, including the dependent data, should be averaged in the same manner, to ensure that the scales of the dependent and predictor data match.

A related consideration is that, in marine systems, predictor variables measured at one point in time are often the manifestation of earlier dynamics (e.g. phytoplankton enrichment resulting from earlier wave propagation, eddy decay or frontolysis; see Flierl \& McGillycuddy 2002, Olson 2002). A predicted snapshot of a species' distribution may therefore be at least partially a reflection of past conditions, resulting in temporal and spatial mismatch (Grémillet et al. 2008), and will consequently have reduced explanatory power. Such lags, both spatial and temporal, are important, but are often ignored (and understandably so, as they are difficult to characterise). Drawing from a non-marine-mammal example, Walli (2007) used water-mass backtracking to identify time lags of 1 to $3 \mathrm{wk}$ between the peaks in primary production and in foraging activity by Atlantic bluefin tuna Thunnus thynnus in different regions of the North Atlantic. So while the areas where the predator conducted the highest amount of foraging consistently occurred where phytoplankton blooms had previously developed, a zero-lag correlation between the two would have found no statistical significance (Walli 2007). Proper consideration of such lag issues is also crucial for correctly representing the processes of interest.

Secondly, the increasing number of environmental variables available to researchers has led to the formulation of correlative models developed using automatic variable selection techniques (e.g. stepwise and machine learning methods) that extract significant variables from a large number of independent variables. With such 'black box' approaches, explaining why the 'significant' variables are ecologically important can become nearly impossible, particularly when the nature of the relationship (i.e. functional form, potential interactions) is not constrained. Relative significance is also difficult to assess since the variable selection process erodes confidence in the resulting $\mathrm{p}$ values, such that hypothesis testing with such models is ill advised (Whittingham et al. 2006). In addition, interpreting the influence of a particular variable on a species' distribution is difficult because adding or removing other variables can often change the functional relationship between the dependent and independent variables. To better understand the role of the independent variables, one practical approach is to specify separate single-variable models, which avoids corruption of $p$ values and permits much stronger inferences about variable significance (e.g. Baumgartner et al. 2003a). Once significant variables are identified individually (or in small groups), hypotheses can be generated about why they are important, and either process studies or new confirmatory models that use independent data (see below) can be designed to address those hypotheses (Johnson \& Omland 2004). How processes interact across scales can then also be hypothesised and related to the presumed scale of influence. For example, Gregr (2011) described how spatial extent and resolution influenced variable importance in predicting North Pacific right whale habitat: models at the basin scale were driven by distance to underwater canyons, while regional models were more influenced by local ocean climate.

While modest improvements in model performance are likely to be realised with better spatial and temporal scaling, more careful environmental variable selection, and improved or more flexible modeling approaches, the fact remains that correlative applications generally contain little a priori ecological understanding (Dormann et al. 2012). We therefore now consider ways in which we can move beyond correlative models to those based on process.

\section{Confirmatory models}

Hypotheses about how environmentally or behaviourally mediated processes influence marine mammal distributions are ideally developed from process studies, but they can also be suggested by correlative models or an a priori understanding of a species' (or its prey's) ecology gleaned from the literature. Regardless of how these hypotheses are generated, statistical species-habitat models can serve as a useful tool for testing them. We refer to these models as 'confirmatory', as they are meant to confirm (or test) our ideas of what is driving the spatial distribution of a particular species based on the new insights provided by the process studies. Returning to our sperm whale example, demonstrating that sperm whales dive to and forage in the OML (a vertical process) provides an ecological basis for testing the hypothesis that variability in OML depth influences sperm whale horizontal distribution. A confirmatory model, 
then, would be used to examine sperm whale spatial distribution with respect to OML depth to test this hypothesis (the extensibility of the model to other areas would, of course, be limited by the availability of OML data at the relevant scales, but at the very least, the results of the study would highlight the need for such data). For North Atlantic right whales, Baumgartner \& Mate (2003) demonstrated that right whales forage on thin layers of calanoid copepods just above the bottom mixed layer, and Baumgartner et al. (2003a) confirmed that the depth of the bottom mixed layer significantly influenced the spatial distribution of right whales (the addition of this variable increased the model drop in deviance by $29 \%$ ). Similarly, Gregr (2011) used an understanding of North Pacific right whale prey life history and potential oceanographic concentration features gleaned from previous studies reported in the literature to investigate the potential for prey concentration via bathymetric steering.

Since these models are specifically designed to test hypotheses, approaches that allow strong inferences should be used (e.g. the single-variable modeling strategy outlined above; see also Burnham \& Anderson 2002, Johnson \& Omland 2004, Araújo \& New 2007). The generalised linear and additive modeling frameworks that are in wide use today are adequate tools for confirmatory models. In addition, tremendous progress has been made in the past decade in the development of Bayesian information-theoretic methods for modeling complex ecological processes as a viable alternative to the frequentist inference methods so prevalent in correlative models (Ellison 2004). Through hierarchical factorization of processes and parameters into a series of conditional submodels, these methods have the capacity to merge and assimilate diverse types of information, while explicitly incorporating and propagating the sources of error associated with them (Wikle 2003, Clark 2005). In particular, their ability to account for process features such as mean and random effects (including spatial autocorrelation), point versus areal relationships, and spatiotemporal hierarchies, makes them highly appealing for species distribution modeling (Gelfand et al. 2006, Latimer et al. 2006, Diez \& Pulliam 2007). While one of their drawbacks when modeling high-dimensional problems is the computational cost involved in simulation (i.e. Gibbs sampling with the Markov chain Monte Carlo algorithm), the recent implementation of the integrated nested Laplace approximation algorithm makes it now feasible to efficiently fit complex models to spatial ecological problems (Illian et al. 2013).
But what variables (or proxies) and parameterisations should we use to capture processes like socialising, the presence of predators, foraging capabilities or interspecific competition? And how should we incorporate these behaviourally mediated processes into models of species distribution? The challenge of specifying behavioural processes can be overcome with mechanistic formulations, provided the processes can be parameterised from theory, metaanalyses of empirical data or process studies. Because mechanistic models are deterministic, rather than statistical, representations of a system of interest, and because their present applications are somewhat different, we discuss them in the next section while noting their imminent convergence with empirical frameworks.

\section{Mechanistic models and their integration with empirical models}

Important strides are being made in the development of mechanistic formulations that explicitly parameterise biological processes such as physiology (Kearney \& Porter 2009), trophic transfer (Morissette et al. 2010, Morozov et al. 2012), social interactions (New et al. 2013), predator-prey behaviour (Srinivasan et al. 2010, Ferguson et al. 2011, Testa et al. 2012), individual movement (Satterthwaite \& Mangel 2012) and population dynamics (MacCall 1990, Struve et al. 2010). In addition, driven by the needs of the fisheries assessment community, a variety of ecosystem-level modeling frameworks tailored for the marine environment have recently been developed that even permit the inclusion of human activities and climate change impacts (Plagányi 2007, Stock et al. 2011, Morzaria-Luna et al. 2012, Plagányi et al. 2012). These numerical approaches can be efficient tools for addressing theoretical concepts and for investigating how new parameters and their sensitivity play a role in outcomes using alternate model formulations. However, the promise of mechanistic approaches is tempered with their limitations, including the high computational costs, the need for verifiability, their extensibility to areas outside the modeled domain, and the incorporation of uncertainty (Plagányi 2007, Stock et al. 2011, Link et al. 2012). For these reasons, an incremental, iterative process from simple to complex formulations is recommended before spatially explicit models of marine mammal population dynamics incorporating prey abundance and environmental variability can be successfully built (International Whaling Commission 2013). 
Another area under development is the integration of deterministic and statistical approaches into coupled modeling frameworks, the need for which is broadly recognised in the ecological literature (e.g. Jakeman et al. 2006, Evans et al. 2011, Grimm \& Railsback 2011, Robinson et al. 2011, Dormann et al. 2012, Cuddington et al. 2013). One possible approach, so-called hybrid modeling, takes the output from mechanistic models as input for correlative models to predict spatial distributions (e.g. Cheung et al. 2008). In this sense, the hybrid approach is confirmatory (see 'Confirmatory models' above) in that the mechanistic model serves as a kind of process study to inform the statistical model. However, such separate analyses will soon be unnecessary; with the convergence of the Bayesian paradigm with graphical model representations and efficient computational algorithms, the models of the future will be capable of generating inference and dynamic prediction within a single, synthetic approach (Clark \& Gelfand 2006).

\section{CONCLUSION}

We have identified a progression of modeling stages that should lead us to formulate increasingly robust and accurate predictions of marine mammal distributions. At the same time, our choice of model type and level of complexity should be weighed carefully against the research question, the data available and the application (e.g. identifying habitat for conservation, empirical testing of a hypothesis for a novel ecological process, forecasting of future distributions), to ensure that the outputs of our models are used in appropriate and meaningful ways. In addition, our model outputs should also include and quantify their inherent uncertainty. This requirement is no more pressing than when management applications are concerned, where the management goals must reflect the uncertainty levels (see Gerrodette \& Eguchi 2011). Our challenge as a modeling community is then to provide ecologically supported results with the tools and information available to us today, while continuing to develop or adopt more synthetic approaches for integrating environmentally and behaviourally mediated processes in our models. Clearly there are logistical and observational hurdles to obtaining this information on wide-ranging and elusive species. However, such information is critical to elucidating the role of process in marine mammal distributions.

One of our primary goals in organising the Theme Section 'Beyond marine mammal habitat modeling: applications for ecology and conservation' was to demonstrate and celebrate how far the marine mammal community has come in the application of empirical distribution models for both science and management. The contributions in this Theme Section represent a snapshot of the state of the art in marine mammal spatial modeling, and we may use this snapshot to mark our progress in 5, 10 or 20 years time. While it is impossible to envision what the models of the future will be like, we anticipate that prediction accuracy will best be improved by using process studies, confirmatory models, synthetic approaches and more strategic application of model results to further our understanding of the ecology of marine mammals. Given the existing and emerging risks to marine mammals from human activities and climate change, accurate spatial distribution models based on relevant oceanographic and behavioural processes are needed for conservation and management, now more than ever.

Acknowledgements. D.M.P. was supported by funding from the NASA Applied Sciences Program, Earth Science Division, through a grant provided by Research Announcement NNH07ZDA001N, Research Opportunities in Space and Earth Sciences (ROSES-2007), Program Element A.20: Decision Support through Earth Science Research Results. E.J.G. was supported by grants from the Natural Sciences and Engineering Research Council of Canada and the North Pacific Research Board. The ideas expressed in this paper benefited from discussions with R. Mendelssohn and from comments on earlier drafts by M. A. Pardo, W. K. de la Mare, T. Gerrodette, R. S. Schick and an anonymous reviewer. M. A. Pardo and R. S. Schick additionally pointed us to useful references on the topic of hierarchical Bayes.

\section{LITERATURE CITED}

Anderwald P, Evans PGH, Dyer R, Dale A, Wright PJ, Hoelzel AR (2012) Spatial scale and environmental determinants in minke whale habitat use and foraging. Mar Ecol Prog Ser 450:259-274

Araújo MB, New M (2007) Ensemble forecasting of species distributions. Trends Ecol Evol 22:42-47

Barlow J, Gerrodette T, Forcada J (2001) Factors affecting perpendicular sighting distances on shipboard line-transect surveys for cetaceans. J Cetacean Res Manag 3: 201-212

- Baumgartner MF, Mate BR (2003) Summertime foraging ecology of North Atlantic right whales. Mar Ecol Prog Ser 264:123-135

Baumgartner MF, Cole TVN, Clapham PJ, Mate BR (2003a) North Atlantic right whale habitat in the lower Bay of Fundy and on the SW Scotian Shelf during 1999-2001. Mar Ecol Prog Ser 264:137-154

Baumgartner MF, Cole TVN, Campbell RG, Teegarden GJ, Durbin EG (2003b) Associations between North Atlantic right whales and their prey, Calanus finmarchicus, over diel and tidal time scales. Mar Ecol Prog Ser 264:155-166 
Baumgartner MF, Lysiak NSJ, Schuman C, Urban-Rich J, Wenzel FW (2011) Diel vertical migration behavior of Calanus finmarchicus and its influence on right and sei whale occurrence. Mar Ecol Prog Ser 423:167-184

Bearzi M (2006) California sea lions use dolphins to locate food. J Mammal 87:606-617

Beaumont LJ, Hughes L, Pitman AJ (2008) Why is the choice of future climate scenarios for species distribution modeling important? Ecol Lett 11:1135-1146

Benoit-Bird KJ, Au WW (2003) Prey dynamics affect foraging by a pelagic predator (Stenella longirostris) over a range of spatial and temporal scales. Behav Ecol Sociobiol 53:364-373

Benoit-Bird KJ, Au WWL (2006) Extreme diel horizontal migrations by a tropical nearshore resident micronekton community. Mar Ecol Prog Ser 319:1-14

> Benoit-Bird KJ, Battaile BC, Heppell SA, Hoover B and others (2013) Prey patch patterns predict habitat use by top marine predators with diverse foraging strategies. PLoS ONE 8:e53348

Biuw M, Boehme L, Guinet C, Hindell M and others (2007) Variations in behaviour and condition of a Southern Ocean top predator in relation to in situ oceanographic conditions. Proc Natl Acad Sci USA 104:13705-13710

> Blasi MF, Boitani L (2012) Modelling fine-scale distribution of the bottlenose dolphin Tursiops truncatus using physiographic features on Filicudi (southern Thyrrenian Sea, Italy). Endang Species Res 17:269-288

Boyce MS, Pitt J, Northrup JM, Morehouse AT, Knopff KH, Cristescu B, Stenhouse GB (2010) Temporal autocorrelation functions for movement rates from global positioning system radiotelemetry data. Philos Trans R Soc Lond B Biol Sci 365:2213-2219

Burnham KP, Anderson DR (2002) Model selection and multimodel inference: a practical information-theoretic approach. Springer, New York, NY

> Cheung WWL, Close C, Lam V, Watson R, Pauly D (2008) Application of macroecological theory to predict effects of climate change on global fisheries potential. Mar Ecol Prog Ser 365:187-197

> Ciano JN, Jørgensen R (2000) Observations on an interaction between a humpback whale (Megaptera novaeangliae) and pilot whales (Globicephala melas). Mar Mamm Sci 16:245-248

> Clark JS (2005) Why environmental scientists are becoming Bayesians. Ecol Lett 8:2-14

Clark JS, Gelfand AE (2006) A future for models and data in environmental science. Trends Ecol Evol 21:375-380

Connor RC, Smolker RA, Richards AF (1992) Two levels of alliance formation among male bottlenose dolphins (Tursiops sp.). Proc Natl Acad Sci USA 89:987-990

Croll DA, Tershy BR, Hewitt RP, Demer DA and others (1998) An integrated approach to the foraging ecology of marine birds and mammals. Deep-Sea Res II 45: 1353-1371

> Croll DA, Clark CW, Acevedo A, Tershy B, Flores S, Gedamke J, Urban J (2002) Only male fin whales sing loud songs. Nature 417:809

Cuddington K, Fortin MJ, Gerber LR, Hastings A, Liebhold A, O'Connor M, Ray C (2013) Process-based models are required to manage ecological systems in a changing world. Ecosphere 4:art20

> Diez JM, Pulliam HR (2007) Hierarchical analysis of species distributions and abundance across environmental gradients. Ecology 88:3144-3152
Doney SC, Glover DM, McCue SJ, Fuentes M (2003) Mesoscale variability of Sea-viewing Wide Field-of-view Sensor (SeaWiFS) satellite ocean color: global patterns and spatial scales. J Geophys Res 108:3024, doi: 10.1029/ 2001JC000843

Doniol-Valcroze T, Lesage V, Giard J, Michaud R (2012) Challenges in marine mammal habitat modelling: evidence of multiple foraging habitats from the identification of feeding events in blue whales. Endang Species Res 17:255-268

Dormann CF, Schymanski SJ, Cabral J, Chuine I and others (2012) Correlation and process in species distribution models: bridging a dichotomy. J Biogeogr 39:2119-2131

Elith J, Leathwick JR (2009) Species distribution models: ecological explanation and prediction across space and time. Annu Rev Ecol Evol Syst 40:677-697

Elith J, Graham C, Anderson R, Dudík M and others (2006) Novel methods improve prediction of species' distributions from occurrence data. Ecography 29:129-151

> Ellison AM (2004) Bayesian inference in ecology. Ecol Lett 7 : 509-520

- Engelhaupt D, Hoelzel RA, Nicholson C, Frantzis A and others (2009) Female philopatry in coastal basins and male dispersion across the North Atlantic in a highly mobile marine species, the sperm whale (Physeter macrocephalus). Mol Ecol 18:4193-4205

> Estes JA, Tinker MT, Williams TM, Doak DF (1998) Killer whale predation on sea otters linking oceanic and nearshore ecosystems. Science 282:473-476

> Etnoyer P, Canny D, Mate BR, Morgan LE, Ortega-Ortíz JG, Nichols WJ (2006) Sea-surface temperature gradients across blue whale and sea turtle foraging trajectories off the Baja California Peninsula, Mexico. Deep-Sea Res II 53:340-358

> Evans MR, Norris KJ, Benton TG (2011) Predictive ecology: systems approaches. Philos Trans R Soc Lond B Biol Sci 367:163-169

Fauchald P, Erikstad KE, Skarsfjord H (2000) Scale-dependent predator-prey interactions: the hierarchical spatial distribution of seabirds and prey. Ecology 81:773-783

Ferguson SH, Kingsley MCS, Higdon JW (2011) Killer whale (Orcinus orca) predation in a multi-prey system. Popul Ecol 54:31-41

Flierl G, McGillycuddy DJ (2002) Mesoscale and submesoscale physical-biological interactions. In: Robinson AR, McCarthy JJ, Rothschild BJ (eds) The sea. John Wiley \& Sons, New York, NY, p 113-185

Foley MM, Halpern BS, Micheli F, Armsby MH and others (2010) Guiding ecological principles for marine spatial planning. Mar Policy 34:955-966

Forcada J (2008) Distribution. In: Perrin WF, Würsig B, Thewissen JGM (eds) Encyclopedia of marine mammals, 2nd edn. Academic Press, Burlington, MA, p 316-321

Frantzis A, Herzing DL (2002) Mixed-species associations of striped dolphins (Stenella coeruleoalba), short-beaked common dolphins (Delphinus delphis), and Risso's dolphins (Grampus griseus) in the Gulf of Corinth (Greece, Mediterranean Sea). Aquat Mamm 28:188-197

Gelfand AE, Silander JA, Wu S, Latimer A, Lewis PO, Rebelo AG, Holder H (2006) Explaining species distribution patterns through hierarchical modeling. Bayesian Anal 1:41-92

Gerrodette T, Eguchi T (2011) Precautionary design of a marine protected area based on a habitat model. Endang Species Res 15:159-166 
Goldbogen JA, Friedlaender AS, Calambokidis J, McKenna MF, Simon M, Nowacek DP (2013) Integrative approaches to the study of baleen whale diving behavior, feeding performance, and foraging ecology. Bioscience 63:90-100

Gomis D, Pedder M (2005) Errors in dynamical fields inferred from oceanographic cruise data. Part I. The impact of observation errors and the sampling distribution. J Mar Syst 56:317-333

Gomis D, Pascual A, Pedder M (2005) Errors in dynamical fields inferred from oceanographic cruise data. Part II. The impact of the lack of synopticity. J Mar Syst 56: 334-351

Gregr EJ (2011) Insights into North Pacific right whale Eubalaena japonica habitat from historic whaling records. Endang Species Res 15:223-239

> Gregr EJ, Coyle KO (2009) The biogeography of the North Pacific right whale (Eubalaena japonica). Prog Oceanogr 80:188-198

Gregr EJ, Baumgartner MF, Laidre KL, Palacios DM (2013) Marine mammal habitat models come of age: the emergence of ecological and management relevance. Endang Species Res 22:205-212

Grémillet D, Lewis S, Drapeau L, van Der Lingen C and others (2008) Spatial match-mismatch in the Benguela upwelling zone: Should we expect chlorophyll and seasurface temperature to predict marine predator distributions? J Appl Ecol 45:610-621

Grimm V, Railsback SF (2011) Pattern-oriented modeling: a 'multi-scope' for predictive systems ecology. Philos Trans R Soc Lond B Biol Sci 367:298-310

Guisan A, Zimmermann NE (2000) Predictive habitat distribution models in ecology. Ecol Model 135:147-186

Haynes TB, Nelson SK, Padula VM (2011) Dynamics of multi-species feeding associations in marine waters near Juneau, Alaska. Mar Ornithol 39:227-234

> Hazen EL, Nowacek DP, St Laurent L, Halpin PN, Moretti DJ (2011) The relationship among oceanography, prey fields, and beaked whale foraging habitat in the Tongue of the Ocean. PLoS ONE 6:e19269

$>$ Heide-Jørgensen MP, Laidre KL, Wiig $\varnothing$, Postma L, Dueck L, Bachmann L (2010) Large-scale sexual segregation of bowhead whales. Endang Species Res 13:73-78

Heithaus MR (2001) Predator-prey and competitive interactions between sharks (order Selachii) and dolphins (suborder Odontoceti): a review. J Zool 253:53-68

> Hewitt JE, Thrush SF, Dayton PK, Bonsdorff E (2007) The effect of spatial and temporal heterogeneity on the design and analysis of empirical studies of scale dependent systems. Am Nat 169:398-408

- Hirche HJ (1996) Diapause in the marine copepod, Calanus finmarchicus - a review. Ophelia 44:129-143

> Hosoda K, Kawamura H (2004) Global space-time statistics of sea surface temperature estimated from AMSR-E data. Geophys Res Lett 31:L17202, doi:10.1029/2004GL 020317

Illian JB, Martino S, Sørbye SH, Gallego-Fernández JB, Zunzunegui M, Esquivias MP, Travis JMJ (2013) Fitting complex ecological point process models with integrated nested Laplace approximation. Methods Ecol Evol 4: 305-315

International Whaling Commission (2013) Report of the Scientific Committee. Annex K1: Report of the Working Group on Ecosystem Modeling. J Cetacean Res Manag 14(Suppl):268-272
Jakeman AJ, Letcher RA, Norton JP (2006) Ten iterative steps in development and evaluation of environmental models. Environ Model Softw 21:602-614

Janik VM, Slater PJB (1998) Context-specific use suggests that bottlenose dolphin signature whistles are cohesion calls. Anim Behav 56:829-838

Jaquet N, Whitehead H (1996) Scale-dependent correlation of sperm whale distribution with environmental features and productivity in the South Pacific. Mar Ecol Prog Ser 135:1-9

Jefferson TA, Stacey PJ, Baird RW (1991) A review of killer whale interactions with other marine mammals - predation to coexistence. Mammal Rev 21:151-180

Johnson JB, Omland KS (2004) Model selection in ecology and evolution. Trends Ecol Evol 19:101-108

Johnson M, Aguilar de Soto N, Madsen PT (2009) Studying the behaviour and sensory ecology of marine mammals using acoustic recording tags: a review. Mar Ecol Prog Ser 395:55-73

Kaschner K, Watson R, Trites AW, Pauly D (2006) Mapping world-wide distributions of marine mammal species using a relative environmental suitability (RES) model. Mar Ecol Prog Ser 316:285-310

Kearney M, Porter W (2009) Mechanistic niche modeling: combining physiological and spatial data to predict species' ranges. Ecol Lett 12:334-350

- Keller CA, Garrison L, Baumstark R, Ward-Geiger LI, Hines E (2012) Application of a habitat model to define calving habitat of the North Atlantic right whale in the southeastern United States. Endang Species Res 18: 73-87

Laidre KL, Heide-Jørgensen MP, Logdson ML, Hobbs RC and others (2004) Seasonal narwhal habitat associations in the high Arctic. Mar Biol 145:821-831

Laidre KL, Heide-Jørgensen MP, Orr J (2006) Reactions of narwhals, Monodon monoceros, to killer whale, Orcinus orca, attacks in the eastern Canadian High Arctic. Can Field Nat 120:457-465

Laidre KL, Heide-Jørgensen MP, Gissel Nielsen T (2007) Role of the bowhead whale as a predator in West Greenland. Mar Ecol Prog Ser 346:285-297

Laidre KL, Born EW, Gurarie E, Wiig O, Dietz R, Stern H (2012) Females roam while males patrol: divergence in breeding season movements of pack-ice polar bears (Ursus maritimus). Proc R Soc Lond B Biol Sci 280: 20122371

Lambert E, MacLeod CD, Hall K, Brereton T and others (2011) Quantifying likely cetacean range shifts in response to global climatic change: implications for conservation strategies in a changing world. Endang Species Res 15:205-222

> Latimer AM, Wu S, Gelfand AE, Silander JA Jr (2006) Building statistical models to analyze species distributions. Ecol Appl 16:33-50

Le Boeuf BJ, Crocker DE, Costa DP, Blackwell SB, Webb PM, Houser DS (2000) Foraging ecology of northern elephant seals. Ecol Monogr 70:353-382

Levin PS, Fogarty MJ, Murawski SA, Fluharty D (2009) Integrated ecosystem assessments: developing the scientific basis for ecosystem-based management of the ocean. PLoS Biol 7:e1000014

Link JS, Ihde TF, Harvey CJ, Gaichas SK and others (2012) Dealing with uncertainty in ecosystem models: the paradox of use for living marine resource management. Prog Oceanogr 102:102-114 
MacCall AD (1990) Dynamic geography of marine fish populations. University of Washington Press, Seattle, WA

- McClenachan L, Cooper AB (2008) Extinction rate, historical population structure and ecological role of the Caribbean monk seal. Proc R Soc Lond B Biol Sci 275: 1351-1358

Moore S, Lien R (2007) Pilot whales follow internal solitary waves in the South China Sea. Mar Mamm Sci 23: 193-196

> Morin X, Lechowicz MJ (2008) Contemporary perspectives on the niche that can improve models of species range shifts under climate change. Biol Lett 4:573-576

> Morissette L, Kaschner K, Gerber LR (2010) Ecosystem models clarify the trophic role of whales off Northwest Africa. Mar Ecol Prog Ser 404:289-302

Morozov A, Poggiale JC, Cordoleani F (2012) Implementation of the zooplankton functional response in plankton models: state of the art, recent challenges and future directions. Prog Oceanogr 103:80-91

> Morzaria-Luna HN, Ainsworth CH, Kaplan IC, Levin PS, Fulton EA (2012) Exploring trade-offs between fisheries and conservation of the vaquita porpoise (Phocoena sinus) using an Atlantis ecosystem model. PLoS ONE 7: e42917

Murawski SA, Steele JH, Taylor P, Fogarty MJ, Sissenwine MP, Ford M, Suchman C (2010) Why compare marine ecosystems? ICES J Mar Sci 67:1-9

> Myers RA (1998) When do environment-recruitment correlations work? Rev Fish Biol Fish 8:285-305

$>$ New LF, Harwood J, Thomas L, Donovan C and others (2013) Modeling the biological significance of behavioural change in coastal bottlenose dolphins in response to disturbance. Funct Ecol 27:314-322

Olson DB (2002) Biophysical dynamics of ocean fronts. In: Robinson AR, McCarthy JJ, Rothschild BJ (eds) The sea. John Wiley \& Sons, New York, NY, p 187-218

Palacios DM, Mate BR (1996) Attack by false killer whales (Pseudorca crassidens) on sperm whales (Physeter macrocephalus) in the Galápagos Islands. Mar Mamm Sci 12:582-587

> Palacios DM, Bograd S, Foley D, Schwing F (2006) Oceanographic characteristics of biological hot spots in the North Pacific: a remote sensing perspective. Deep-Sea Res II 53:250-269

Papastavrou V, Smith SC, Whitehead H (1989) Diving behaviour of the sperm whale, Physeter macrocephalus, off the Galapagos Islands. Can J Zool 67:839-846

> Parsons KM, Balcomb KC, Ford JKB, Durban JW (2009) The social dynamics of southern resident killer whales and conservation implications for this endangered population. Anim Behav 77:963-971

Payne R, Webb D (1971) Orientation by means of long range acoustic signaling in baleen whales. Ann N Y Acad Sci 188:110-141

Pitman RL, Ballance LT (1992) Parkinson's petrel distribution and foraging ecology in the eastern Pacific: aspects of an exclusive feeding relationship with dolphins. Condor 94:825-835

Plagányi ÉE (2007) Models for an ecosystem approach to fisheries. Fish Tech Pap 477. FAO, Rome

Plagányi ÉE, Punt AE, Hillary R, Morello EB and others (2012) Multispecies fisheries management and conservation: tactical applications using models of intermediate complexity. Fish Fish, doi:10.1111/j.1467-2979.2012. 00488.x
Ramp C, Hagen W, Palsbøll P, Bérubé M, Sears R (2010) Age-related multi-year associations in female humpback whales (Megaptera novaeangliae). Behav Ecol Sociobiol 64:1563-1576

- Rasmussen K, Palacios DM, Calambokidis J, Saborío M and others (2007) Southern Hemisphere humpback whales wintering off Central America: insights from water temperature into the longest mammalian migration. Biol Lett 3:302-305

$>$ Redfern JV, Ferguson MC, Becker EA, Hyrenbach KD and others (2006) Techniques for cetacean-habitat modeling. Mar Ecol Prog Ser 310:271-295

Robinson LM, Elith J, Hobday AJ, Pearson RG, Kendall BE, Possingham HP, Richardson AJ (2011) Pushing the limits in marine species distribution modeling: lessons from the land present challenges and opportunities. Glob Ecol Biogeogr 20:789-802

- Robinson PW, Costa DP, Crocker DE, Gallo-Reynoso JP and others (2012) Foraging behavior and success of a mesopelagic predator in the Northeast Pacific Ocean: insights from a data-rich species, the northern elephant seal. PLoS ONE 7:e36728

Rossi-Santos MR, Santos-Neto E, Baracho CG (2009) Interspecific cetacean interactions during the breeding season of humpback whale (Megaptera novaeangliae) on the north coast of Bahia State, Brazil. J Mar Biol Assoc UK 89:961-966

Satterthwaite WH, Mangel M (2012) Behavioral models as a common framework to predict impacts of environmental change on seabirds and fur seals. Deep-Sea Research II 65-70:304-315

Scott MD, Chivers SJ, Olson RJ, Fiedler PC, Holland K (2012) Pelagic predator associations: tuna and dolphins in the eastern tropical Pacific Ocean. Mar Ecol Prog Ser 458:283-302

> Shelden KE, Baldridge A, Withrow DE (1995) Observations of Risso's dolphins, Grampus griseus with gray whales, Eschrictius robustus. Mar Mamm Sci 11:231-240

Slotte A (1999) Effects of fish length and condition on spawning migration in Norwegian spring spawning herring (Clupea harengus L.). Sarsia 84:111-127

Srinivasan M, Grant WE, Swannack TM, Rajan J (2010) Behavioral games involving a clever prey avoiding a clever predator: an individual-based model of dusky dolphins and killer whales. Ecol Model 221:2687-2698

Stock CA, Alexander MA, Bond NA, Brander KM and others (2011) On the use of IPCC-class models to assess the impact of climate on Living Marine Resources. Prog Oceanogr 88:1-27

- Struve J, Lorenzen K, Blanchard J, Börger L and others (2010) Lost in space? Searching for directions in the spatial modeling of individuals, populations and species ranges. Biol Lett 6:575-578

Testa JW, Mock KJ, Taylor C, Koyuk H, Coyle JR, Waggoner R (2012) Agent-based modeling of the dynamics of mammal-eating killer whales and their prey. Mar Ecol Prog Ser 466:275-291

> Torres LG, Read AJ, Halpin P (2008) Fine-scale habitat modeling of a top marine predator: Do prey data improve predictive capacity? Ecol Appl 18:1702-1717

> Turvey ST, Pitman RL, Taylor BL, Barlow J and others (2007) First human-caused extinction of a cetacean species? Biol Lett 3:537-540

> Vaughn RL, Shelton DE, Timm LL, Watson LA, Würsig B (2007) Dusky dolphin (Lagenorhynchus obscurus) feed- 
ing tactics and multi species associations. NZ J Mar Freshw Res 41:391-400

Verity PG, Smetacek V, Smayda TJ (2002) Status, trends and the future of the marine pelagic ecosystem. Environ Conserv 29:207-237

Walli AG (2007) On the movements, aggregations and the foraging habitat of bluefin tuna (Thunnus thynnus \& $T$. orientalis). $\mathrm{PhD}$ dissertation, University of California Santa Cruz, CA

Wells RS, Scott MD, Irvine AB (1987) The social structure of free-ranging bottlenose dolphins. In: Genoways HH (ed) Current mammalogy. Plenum Press, New York, NY, p 247-304

Whittingham MJ, Stephens PA, Bradbury RB, Freckleton RP (2006) Why do we still use stepwise modeling in ecology and behaviour? J Anim Ecol 75:1182-1189

> Wiens JA (1989) Spatial scaling in ecology. Funct Ecol 3: 385-397

Editorial responsibility: Brendan Godley,

University of Exeter, Cornwall Campus, UK
Wikle CK (2003) Hierarchical Bayesian models for predicting the spread of ecological processes. Ecology 84: 1382-1394

Williams R, Leaper R, Zerbini AN, Hammond PS (2007) Methods for investigating measurement error in cetacean line-transect surveys. J Mar Biol Assoc UK 87:313-320

> Wingfield DK, Peckham SH, Foley DG, Palacios DM and others (2011) The making of a productivity hotspot in the coastal ocean. PLoS ONE 6:e27874

Wirsing AJ, Heithaus MR, Frid A, Dill LM (2008) Seascapes of fear: evaluating sublethal predator effects experienced and generated by marine mammals. Mar Mamm Sci 24:1-15

Wishner KF, Schoenherr JR, Beardsley R, Chen C (1995) Abundance, distribution and population structure of the copepod Calanus finmarchicus in a springtime right whale feeding area in the southwestern Gulf of Maine. Cont Shelf Res 15:475-507

Submitted: July 29, 2013; Accepted: October 21, 2013 Proofs received from author(s): November 26, 2013 